\title{
Rationale and Design of a Randomized Controlled Trial to Evaluate the Effects of Probiotics during Energy Restriction on Blood Pressure, Body Composition, Metabolic Profile and Vascular Function in Obese Hypertensive Individuals
}

\author{
Marcella Rodrigues Guedes ${ }^{1}$, Karine Scanci da Silva Pontes ${ }^{1}$, Débora Cristina Torres Valença ${ }^{1}$, Wille Oigman ${ }^{2}$, \\ Mario Fritsch Neves ${ }^{2,(D)}$, Márcia Regina Simas Torres Klein ${ }^{3, *},(\mathbb{D})$ \\ ${ }^{1}$ Discipline of Clinical and Experimental Pathophysiology, State University of Rio de Janeiro, Avenida Vinte e Oito de Setembro, \\ 77 - rooms 361 and 363, Vila Isabel, Rio de Janeiro, RJ, Brazil \\ ${ }^{2}$ Department of Clinical Medicine, State University of Rio de Janeiro, Avenida Vinte e Oito de Setembro, 77, room 329, Vila Isabel, Rio de Janeiro, RJ, Brazil \\ ${ }^{3}$ Department of Applied Nutrition, Nutrition Institute, State University of Rio de Janeiro, Avenida Vinte e Oito de Setembro, \\ 77 - rooms 361 and 363, Vila Isabel, Rio de Janeiro, RJ, Brazil
}

\section{ARTICLE INFO}

Article History

Received 30 December 2019

Accepted 21 April 2020

Keywords

Hypertension

obesity

probiotics

metabolic profile

vascular function

\begin{abstract}
Introduction: Hypertension often clusters with other cardiovascular risk factors such as obesity, dyslipidemia and glucose intolerance. Weight loss can decrease Blood Pressure (BP) and improve cardiometabolic abnormalities. There is evidence that hypertension and obesity are associated with alterations in gut microbiome. Recent studies evaluating the effects of probiotics on BP, body weight, metabolic profile, inflammatory biomarkers, endothelial function and arterial stiffness found inconsistent results, probably due to the wide heterogeneity in trials design. To date, it is not known if probiotics can potentiate the effects of energy restriction in individuals with increased risk of metabolic, inflammatory and vascular abnormalities such as individuals presenting hypertension and obesity.
\end{abstract}

Objective: To evaluate the effects of probiotics during energy restriction on BP, body adiposity (total, central and visceral), insulin resistance, lipid profile, microvascular reactivity and arterial stiffness in obese hypertensive subjects.

Methods: This 12-week randomized, double-blind, controlled clinical trial with obese hypertensive adults, instructed to follow an energy-reduced diet $(-800 \mathrm{Kcal} /$ day $)$ will be conducted at State University of Rio de Janeiro, Brazil. Probiotics and control groups will take one capsule/day containing nine freeze-dried probiotic strains and cellulose, respectively. At baseline and at the end of the study, participants will undergo nutritional, laboratory, BP and vascular evaluation. Nutritional assessment will include bioelectrical impedance analysis and dual energy X-ray absorptiometry. Laboratory parameters will include glucose, insulin, lipid profile, C-reactive protein, adiponectin, tumor necrosis factor alpha, interleukin-6 and lipopolysaccharide. Postocclusive microvascular reactivity will be evaluated by laser speckle contrast imaging and oscillometric pulse wave analysis by Mobil-O-Graph.

(c) 2020 Association for Research into Arterial Structure and Physiology. Publishing services by Atlantis Press International B.V. This is an open access article distributed under the CC BY-NC 4.0 license (http://creativecommons.org/licenses/by-nc/4.0/)

\section{INTRODUCTION}

Cardiovascular Diseases (CVDs) continue to be the leading cause of global mortality [1]. Hypertension affects almost one third of adult population [2] and is a major risk factor for almost all CVDs [3], being an important cause of death and disability-adjusted life years worldwide [1,4]. Data from observational studies have already demonstrated a strong linear positive association between Blood Pressure (BP) and CVDs [3,5].

"Corresponding author.Email: marciarsimas@gmail.com

Peer review under responsibility of the Association for Research into Arterial Structure and Physiology

Data availability statement: Data sharing is not applicable to this article as no new data were created or analyzed in this study.
Hypertension often clusters with other CVDs risk factors such as overweight/obesity, dyslipidemia and glucose intolerance [6,7]. The relationship between hypertension and other CVDs risk factors is complex [6]. A nearly linear relationship exists between BP and indices of obesity. Excessive weight gain, especially when associated with visceral obesity, raises BP and is the most important known risk factor for primary (essential) hypertension [8]. The mechanisms of obesity induced hypertension have not been fully elucidated. However, several consequences of obesity may interact synergistically with hypertension favoring CVDs. These consequences include increased activity of sympathetic nervous system and of renin-angiotensin system, metabolic abnormalities (dyslipidemia and insulin resistance), inflammation, lipotoxicity, endothelial dysfunction and arterial stiffness [8-11]. 
Weight loss lowers BP even without attainment of a desirable body weight [12]. In a meta-analysis, an average weight loss of $5.1 \mathrm{~kg}$ reduced Systolic BP (SBP) by $4.4 \mathrm{~mm} \mathrm{Hg}$ and Diastolic BP (DBP) by $3.6 \mathrm{mmHg}$ [13]. Weight loss in obese individuals can also improve metabolic abnormalities, inflammatory profile and endothelial dysfunction [14,15]. Lifestyle intervention is a critical component of weight loss therapy and a reduced total energy intake should be the main component of any weight-loss intervention [9].

There is evidence that alterations in gut microbiome (dysbiosis) are associated with obesity, hypertension, arterial stiffness and other cardiometabolic risk factors [16-22]. Several mechanisms have been proposed to explain the association between gut dysbiosis and risk of CDVs, including Lipopolysaccharide (LPS), a component of the membrane of Gram-negative bacteria, and Trimethylamine $\mathrm{N}$-oxide (TMAO), a metabolite produced by the gut microbiota. LPS was associated with chronic inflammation $[23,24]$, while TMAO with endothelial dysfunction, atherosclerosis, and cardiovascular events and mortality [10,25-27]. These findings suggest that the modulation of the gut microbiome can be a new therapeutic tool for weight loss and for the reduction in BP and cardiovascular risk.

The gut microbiome can be modulated by the administration of probiotics, which are defined as "live microorganisms that, when administered in adequate amounts, confer a health benefit on the host" [28]. Although, in recent years, several studies have investigated the effects of probiotics on body adiposity [29-35], glycemic control and insulin resistance [32,35-37], lipid profile $[31,38]$, inflammatory biomarkers $[31,37,39,40]$, BP $[38,41,42]$, endothelial function $[43,44]$ and arterial stiffness [45], their results are inconsistent, probably due to the wide heterogeneity in trials design (duration of the study, dose and strains of probiotics). It is noteworthy that there is a lack of studies investigating if probiotics can potentiate the effects of energy restriction in individuals presenting high risk of metabolic, inflammatory and vascular abnormalities such as individuals presenting obesity and hypertension.

The primary aim of this study is to evaluate the effects of probiotics during energy restriction on BP in obese hypertensive individuals. Secondary objectives are related to the effects of probiotics during energy restriction on body adiposity (total, central and visceral), insulin resistance, lipid profile, inflammatory markers, cutaneous microvascular reactivity, arterial stiffness and fecal microbiota composition in obese hypertensive subjects.

\section{MATERIALS AND METHODS}

\subsection{Trial Design}

This is a 12-week, single-center, parallel, double-blind, randomized placebo-controlled trial that will be conducted at the Laboratory of Clinical and Experimental Pathophysiology, located at State University of Rio de Janeiro, Brazil. Recruitment began in November 2019 and is expected to continue until November 2020. The trial was approved by the Committee on Ethics and Research of the Pedro Ernesto University Hospital (CAAE: 02752118.0.0000.5259) and was registered at www. ensaiosclinicos.gov.br (RBR-7jw4ry). All participants will provide written informed consent.

\subsection{Study Population, Recruitment and Screening}

Eligible participants for the trial are obese hypertensive individuals who meet the enrollment criteria detailed in Table 1. Potential participants, who meet initial eligibility criteria (preliminary evaluation) and agree to take part in the study, will be scheduled for a screening visit (V0) in order to evaluate other eligibility criteria. At this screening visit, they will arrive at the laboratory after a 12-h fasting period for clinical, anthropometric and laboratory evaluations. The following week, participants who fulfill all inclusion criteria will be scheduled to perform the first study visit (V1) and will receive the necessary instructions: take stool sample, 12-h fasting and alcohol abstinence for the previous 3 days.

\subsection{Randomization and Blinding}

At V1, participants will be randomly allocated in 1:1 ratio in blocks to receive capsules containing either probiotics (probiotics group) or placebo (control group). A computer random number generator was used to generate the random sequence for group allocation. Participants and researchers will be blinded to group allocation during the study. Group assignment will be concealed until completion of the statistical analyses. The allocation sequence will also be concealed, using sequentially numbered opaque, sealed envelopes that will be opened only after they have been irreversibly assigned to a participant. Both groups will be evaluated at baseline (V1) and at weeks 4 (V2), 8 (V3) and 12 (V4).

\subsection{Trial Visits}

At baseline (V1), participants will be submitted to nutritional, laboratory, BP and vascular assessment. During this visit, patients will

Table $1 \mid$ Inclusion and exclusion criteria

\begin{tabular}{l}
\hline Inclusion criteria \\
\hline Age $\geq 40$ and $\leq 65$ years \\
Men and women (post-menopausal) \\
Body mass index $\geq 30.0$ and $\leq 39.9 \mathrm{~kg} / \mathrm{m}^{2}$ \\
Previous diagnosis of essential hypertension \\
Treatment with the same antihypertensive drugs for at least 4 weeks \\
\hline Exclusion criteria \\
\hline Individuals with evidence of secondary hypertension or presenting \\
blood pressure $\geq 160 / 100$ mmHg \\
Diabetes mellitus and/or use of insulin or oral hypoglycemic agents \\
Malignant or autoimmune diseases \\
Chronic kidney or liver diseases \\
Clinical signs of heart failure or of changes in thyroid function \\
Current or former smokers (quit $<12$ months) \\
Physical activity practitioners \\
Vegetarians \\
Pregnant or lactating women \\
Use of probiotics, prebiotics, symbiotics, antibiotics, hypolipidemic \\
drugs, hormone replacement therapy, proton pump inhibitors, \\
antioxidant and/or anti-inflammatory supplements including \\
vitamin, mineral or omega 3 in the last 3 months \\
Recent changes (last 3 months) in body weight ( $\geq 3$ kg) and/or in \\
food intake
\end{tabular}


give a stool sample, will be instructed to follow an energy reduced diet, and will receive the capsules (with or without probiotics) for the first 4 weeks of the study. At V2 and V3, participants will be submitted to anthropometric and BP evaluation, and will receive the capsules for the next 4 weeks. At V4, participants will give a new stool sample and will be submitted to all the evaluations performed at V1, as shown in Figure 1.

\subsection{Trial Procedures}

\subsubsection{Probiotic intervention}

The probiotics group will receive capsules containing nine freezedried probiotic strains (each one $10^{9} \mathrm{UFC} /$ capsule): Lactobacillus acidophilus LA-G80, Lactobacillus gasseri LG-G12, Lactobacillus paracasei LPc-G110, Lactobacillus plantarum LP-G18, Lactobacillus delbrueckii LB-G40, Bifidobacterium lactis BL-G101, Bifidobacterium bifidum BB-G90, Bifidobacterium longum BL-G301 and Bifidobacterium infantis BI-G210. The placebo group will receive similar capsules (color, shape and size) without probiotic strains (microcrystalline cellulose).

Both groups will be asked to take one capsule a day, 30 min before breakfast. The indirect method of capsule counting will be used to evaluate the intervention compliance. During the study period, all participants will be instructed to avoid products containing probiotic, prebiotic or symbiotic as well as food rich in polyphenols.

\subsubsection{Dietary prescription}

Both groups will be instructed to follow an energy reduced diet during the 12 weeks of the study. The Total Energy Value (TEV) of the diet prescribed for each study participant will be determined by subtracting $800 \mathrm{Kcal} /$ day from the total daily energy expenditure, which will be estimated using the Dietary Reference Intake (DRI) equations with current body weight [46]. The distribution of macronutrients will be as follows: protein $15-20 \%$ of TEV, lipids $25-30 \%$ of TEV and carbohydrates 50-60\% of TEV. At visits 2 and 3, TEV of the diet will be adjusted according to the participant's body weight at these visits, as an attempt to maintain weight loss.

\subsubsection{Assessment of food intake}

The dietary intake will be assessed by three intervieweradministered $24 \mathrm{~h}$ dietary recalls (two weekdays and one weekend day) at the beginning (V1) and at the end of the study (V4). The three $24 \mathrm{~h}$ dietary recalls obtained at V1 will be used to assess habitual consumption, while the three $24 \mathrm{~h}$ dietary recalls at V4 will be used to assess adherence to the prescribed diet.

The $24 \mathrm{~h}$ recalls will be obtained face-to-face or through telephone call. The recalls will be obtained by two dietitians trained to ask the patients to enumerate all the information about the food and drink they had consumed from midnight to midnight in the previous day, including the quantity.

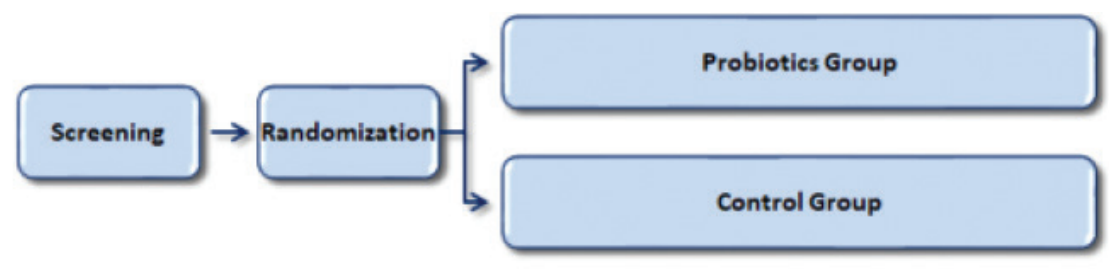

\begin{tabular}{|c|c|c|c|c|c|}
\hline VISIT & 0 & 1 & 2 & 3 & 4 \\
\hline Week & -1 & 0 & 4 & 8 & 12 \\
\hline \multicolumn{6}{|l|}{ Nutritional Assessment } \\
\hline Food intake & & $\mathbf{x}$ & & & $x$ \\
\hline Anthropometry & $\mathbf{x}$ & $\mathbf{x}$ & $\mathbf{x}$ & $x$ & $\mathbf{x}$ \\
\hline Bioelectrical impedance analysis & & $\mathbf{x}$ & & & $x$ \\
\hline Dual-energy X-ray absorptiometry & & $\mathbf{x}$ & & & $\mathbf{x}$ \\
\hline \multicolumn{6}{|l|}{ Laboratory } \\
\hline Blood samples & $\mathbf{x}$ & $x$ & & & $x$ \\
\hline Fecal samples & & $\mathbf{x}$ & & & $x$ \\
\hline Blood Pressure & $\mathbf{x}$ & $\mathbf{x}$ & $\mathbf{x}$ & $\mathbf{x}$ & $x$ \\
\hline \multicolumn{6}{|l|}{ Vascular Assessment } \\
\hline Oscillometric pulse wave analysis & & $\mathbf{x}$ & & & $\mathbf{x}$ \\
\hline Central hemodynamic parameters & & $x$ & & & $x$ \\
\hline Cutaneous microvascular reactivity & & $\mathbf{x}$ & & & $\mathbf{x}$ \\
\hline
\end{tabular}

Figure $1 \mid$ Trial design. 
Nutrient analysis of the $24 \mathrm{~h}$ recalls will be performed using the software Food Processor Plus ${ }^{\circledR}$ (ESHA Research, Salem, Oregon) and two Brazilian Food Composition Tables [47,48].

\subsubsection{Anthropometric measurements}

The anthropometric measurements will be taken twice by two experienced dietitians, and mean values will be used. The height will be measured using a stadiometer accurate to $\pm 0.5 \mathrm{~cm}$ and the weight will be obtained with a digital scale, accurate to $\pm 0.1 \mathrm{~kg}$ (Filizola S.A., São Paulo, SP, Brazil), with the patients wearing light clothing with no shoes and after emptying the bladder. Body Mass Index (BMI) will be calculated using the standard equation $\left(\mathrm{kg} / \mathrm{m}^{2}\right)$ [49]. The measure of the Waist Circumference (WC) will be taken in the standing position midway between the lowest rib and the iliac crest, at mid-exhalation. Hip Circumference (HC) will be measured at the widest point over the hip/buttocks area with the tape parallel to the floor [50]. Waist-to-hip ratio will be determined by dividing WC $(\mathrm{cm})$ by $\mathrm{HC}(\mathrm{cm})$. Waist-to-height ratio will be obtained by dividing WC $(\mathrm{cm})$ by height $(\mathrm{cm})$. The Neck Circumference will be measured in the midway of the neck between mid-cervical spine and mid-anterior neck, if palpable, just below the laryngeal prominence, with participants in the standing position with the head positioned at the Frankfurt horizontal level [51].

\subsubsection{Bioelectrical impedance analysis}

Bioelectrical Impedance Analysis (BIA) procedure will be performed using the Biodynamics BIA-450 body fat analyser (Biodynamics Corp., Seattle, WA, USA) with the patient in the supine position according to manufacturer's instructions. Patients will be advised to fast for at least $8 \mathrm{~h}$ prior the analysis and not to perform strenuous physical activity on the day before the evaluation [52].

Bioelectrical Impedance Analysis is based on the principle that tissues are full of electrolyte-containing fluids and conduct an electric current, measuring two bioelectrical parameters: resistance $(R)$ and reactance $(X) . R$ is the opposition offered by the body to the flow through intra- and extra-cellular ionic solutions of an alternating electrical current, and thus is inversely related to the water and electrolyte content of tissue. $X_{c}$ is the additional opposition related to the capacitance properties of the cell membrane and tissue interfaces, thus depending on its integrity, function, and composition it may influence in variations in $X_{c}$. The relationship between $X_{c}$ and $R$ in circuits is given by the phase angle $(\mathrm{PhA})$, which is independent of body height and weight. PhA varies according to $X_{c}$, thus the lower $X_{c}$ value the lower $\mathrm{PhA}$, indicating body cell loss, and vice-versa [53].

Lean body mass will be estimated using specific predictive equations for individuals with excessive body fat [54,55]. The BIAderived parameters evaluated in the present study will be total body fat, lean mass, PhA, body cell mass, basal metabolic rate, $R, X_{c}$, total body water, intra- and extra-cellular water.

\subsubsection{Dual-energy X-ray absorptiometry}

The Dual-energy X-ray Absorptiometry (DXA) procedure will be performed by a trained technician using a GE Medical Systems
Lunar $^{\circledast}$ (Madison, WI, USA) with the patient in the supine position. The DXA system performs rectilinear scans over the length of the body. The scan begins at the top of the patient's head and moves downward toward the feet. The program allows scanning up to 205 lines. During the scan, the source shutter opens to emit an X-ray beam. The software calculates fat mass, lean tissue and bone mineral mass. Fat-free mass is calculated as the sum of lean tissue plus bone mineral mass. Body composition will be evaluated in total body and different sites, such as trunk. Visceral adipose tissue will be estimated with the software CoreScan VAT [56].

\subsubsection{Habitual physical activity}

The level of habitual physical activity will be evaluated using the International Physical Activity Questionnaire (Short Form). This validated questionnaire [57] will be used in the screening visit (V0) and only individuals classified as sedentary or irregularly active will be included in the study. Both the groups will be advised not to change their usual physical activity during the study period.

\subsubsection{Laboratory parameters}

Blood samples will be analyzed to measure glucose, insulin, Total Cholesterol (TC), High-density Lipoprotein Cholesterol (HDL-C), Triglycerides (TGs), C-Reactive Protein (CRP), adiponectin, resistin, Tumor Necrosis Factor Alpha (TNF- $\alpha$ ), Interleukin-6 (IL-6) and Lipopolysaccharide (LPS). Glucose will be determined by glucose hexokinase method. TC, HDL-C and TGs concentrations will be assessed by using enzymatic colorimetric method. Low-density Lipoprotein Cholesterol (LDL-C) will be estimated by using the Friedewald formula [58]. Insulin will be determined by electro-chemiluminescence immunoassay using commercial kit (Roche Diagnostics, Basel, Switzerland). Insulin resistance status will be assessed using the homoeostasis model assessment of insulin resistance index, which will be calculated as fasting insulin $(\mu \mathrm{U} / \mathrm{ml}) \times$ fasting plasma glucose (mmol/l)/22.5 [59]. CRP will be assessed by turbidimetry method; adiponectin, resistin, TNF- $\alpha$ and IL- 6 by Luminex method (Milliplex Commercial Kit); and LPS by enzyme-linked immunosorbent assay.

\subsubsection{Fecal microbiota assessment}

Stool samples will be collected by the participants at home following written instructions and using a kit provided by the researchers during V0. The samples will be stored at home at temperature of approximately $4^{\circ} \mathrm{C}$ and will be transported to the laboratory under conditions to preserve refrigeration. At the laboratory, stool samples will be immediately stored at $-80^{\circ} \mathrm{C}$ until DNA extraction. Fecal DNA will be extracted using QIAamp Fast DNA Stool Mini Kit (Qiagen, Valencia, CA, USA). Quantitative polymerase chain reaction will be used to identify and quantify bacteria of interest including: Lactobacillus spp, Bifidobacterium spp, Bacteroidetes and Firmicutes.

\subsubsection{Blood pressure measurement}

Systolic and diastolic BP measurements will be obtained with a calibrated electronic device (model HEM-705CP, OMRON Healthcare 
Inc., IL, USA), placed about $2 \mathrm{~cm}$ above the cubital fold. The measurements will be performed with the patient in a sitting position and after 5 min of rest. After six measurements at 1-min interval, standard deviation, coefficient of variation (standard deviation/mean) and amplitude (maximum - minimum) will be obtained as markers of BP variability. Pulse pressure (PP) will be determined from the difference between SBP and DBP. The Mean Arterial Pressure (MAP) will be determined by the equation: $\mathrm{MAP}=\mathrm{DBP}+\mathrm{PP}-3$.

\subsubsection{Oscillometric pulse wave analysis}

Central hemodynamics will be evaluated with the Mobil-O-Graph device (I.E.M. GmbH, Stolberg, Germany). This device has been duly validated for use in scientific research by the European Society of Hypertension. Central hemodynamic parameters will be obtained by a non-invasive method that simultaneously checks the pulse wave of arterial blood flow, allowing the analysis of arterial pressure, Central Systolic Pressure (cSP), Pulse Wave Velocity (PWV) and of the Augmentation Index (AIx) by the ARCsolver method, Austrian Institute of Technology. This method determines cSP based on brachial pulse waves recorded through a cuff attached to the Mobil-O-Graph oscillometric device that checks BP. Recordings are obtained by keeping the cuff inflated for $10 \mathrm{~s}$ at the DBP level using conventional obese adult cuffs and a high-fidelity pressure sensor MPX50550 (Freescale Inc., Tempe, AZ, USA) [60].

Mobil-O-Graph is a device that allows simultaneous measurements of central and peripheral pressure. The following variables will be collected: cSP, Central PP (cPP), pulse pressure amplification, Augmentation Pressure (AP), AIx, AIx@75 (AIx corrected for heart rate of $75 \mathrm{bpm}), \mathrm{PWV}$ and arterial age [61].

\subsubsection{Central hemodynamic parameters}

The central hemodynamics parameters will also be evaluated non-invasively using a commercially available tonometry device (SphygmoCor, AtCor Medical, Sydney, Australia). The SphygmoCor systems utilize a Medical Electronics Module Model EM3, an AtCor Medical/Millar tipped pressure tonometer (Millar Instruments, Houston, TX, USA) and a validated generalized mathematical transfer function to synthesize a central aortic pressure waveform. Participants will be rested quietly in a supine position in a temperature-controlled room for $5 \mathrm{~min}$ prior to initial radial artery pulse pressure waveform analysis. After 10 sequential waveforms will be were acquired, a validated generalized transfer function will be used to generate the corresponding central aortic pressures and pressure waveforms [62]. Aortic SP (aoSP), Aortic PP (aoPP), AP, and AIx will be derived from pulse waveform analysis. AP will be the difference between the second and the first systolic peak pressure, and AIx will be defined as the ratio of AP to aoPP, expressed as a percentage $[\mathrm{AIx}=(\mathrm{AP} / \mathrm{PP}) \times 100]$. In addition, a normalized AIx for a heart rate of 75 beats/min will be derived [63]. Amplification of PP will be calculated by the formula: aoPP/peripheral PP.

\subsubsection{Cutaneous microvascular reactivity}

Cutaneous microvascular reactivity will be assessed after a 20 -min resting period, with subjects lying down in the supine position in a room with temperature control $\left(23 \pm 1^{\circ} \mathrm{C}\right)$ using the laser speckle contrast image with a 785- $\mathrm{mm}$ laser wavelength (PSI Pericam System, Perimed, Sweden). Physiological evaluation of the variations in the microvascular flow will be analyzed using Post-occlusive Reactive Hyperemia (PORH) and will be expressed in Arbitrary Perfusion Units (APU). Values of cutaneous vascular conductance will be obtained by dividing APU by MAP [64]. The image acquisition rate will be one image/s and the distance between the laser head and the skin surface is fixed at $20 \mathrm{~cm}$. A sphygmomanometer will be used over the brachial artery to apply a pressure of $50 \mathrm{mmHg}$ above SBP for $3 \mathrm{~min}$. After rapid decompression, flow changes will be recorded to assess changes in PORH. The flow will then be recorded before (baseline) and after (PORH) the 3-min occlusion period. The manufacturer's software (PIMSoft, Perimed, Sweden) will be used to analyze the images.

\subsection{Statistical Methods}

Categorical variables will be expressed as absolute numbers and percentage. The Shapiro-Wilk test will be used to test the normality of the continuous variables and skewed data will be log transformed to improve normality. Continuous variables with normal distribution will be presented as mean \pm standard errors and those without normal distribution will be presented as median and interquartile range.

Repeated measures analysis of variance will be used to evaluate changes in continuous variables obtained from baseline and postintervention. The Pearson's or Spearman's correlation will be performed to evaluate the association between continuous variables.

The sample size was determined based on the primary outcome of changes in BP, which was obtained from the meta-analysis conducted by $\mathrm{He}$ et al. [38]. A minimum sample size of 24 was determined for each group with a $95 \%-\mathrm{CI}$ and a power of $80 \%$.

\section{DISCUSSION}

In the last decade, significant interest has focused on gut microbiotahost interaction. Accumulating evidence has indicated that the gut microbiome functions like an endocrine organ, generating bioactive metabolites, which can impact host physiology. Gut dysbiosis has been associated with obesity, hypertension, metabolic disturbances, vascular abnormalities and CVDs [16,18]. Therefore, the modulation of gut microbiome with probiotics can be viewed as a new therapeutic tool and the use of probiotic food and supplements has increased in recent years $[65,66]$. Hypertension and obesity frequently coexist, are prevalent among adults and are associated with increased risk of CVDs [6,7]. Although several randomized clinical trials have investigated the effects of probiotics on different health outcomes, it remains unclear whether they can improve cardiometabolic risk factors. The aim of this study is to evaluate the effects of probiotics on BP (main objective), body adiposity, metabolic profile, inflammatory status and vascular parameters in obese hypertensive subjects during energy restriction.

This randomized clinical trial has several potential strengths including the duration of the study, the use of multiple probiotics strains and the inclusion of non-health individuals. In a 
meta-analysis of randomized controlled trials evaluating the effects of probiotics on BP, there was a greater decrease in BP in studies with longer duration ( $\geq 8$ weeks), using multiple strains and conducted with subjects presenting higher levels of BP at baseline [42]. Another meta-analysis also observed a slightly greater effect on SBP in hypertensive participants compared with normotensive ones [41]. Considering studies evaluating the effects of probiotics on lipid profile, recent meta-analyses revealed a statistically greater reduction in TC and LDL-col in trials with longer duration (>8 weeks) [31,67], using multiple probiotics strains $[31,68]$, conducted in individuals with higher baseline TC $[67,69]$ and presenting overweight or obesity [68]. A meta-analysis evaluating the effects of probiotics on weight loss also found greater decrease in body weight in studies during at least 8 weeks [34].

Another potential strength of this study is the evaluation of body composition with DXA, a gold standard method. Although the majority of the studies investigating the effects of probiotics on weight loss and/or metabolic abnormalities evaluated solely anthropometric measures, some studies also evaluated body composition. Among the studies that evaluated body composition, the most used method was BIA [70-73]. So far, only few studies have used DXA to evaluate body composition [33,74]. Andreasen et al. [74] used DXA to evaluate fat-free mass in a study that lasted only 4 weeks, while Kim et al. [33] evaluated changes in body composition during a 12-week study with an energy restriction lower than the present study. Visceral/abdominal adipose tissue has been evaluated using computed tomography in the studies conducted by Kadooka et al. [75] and by Kim et al. [33], while ectopic fat was determined by H-magnetic resonance spectroscopy in the study of Simon et al. [76].

The evaluation of the effects of probiotics on vascular parameters can be considered another strength of this study. To date, despite the existing evidence that TMAO is associated with endothelial dysfunction and increased risk of atherosclerosis and CVDs $[16,77,78]$, only few studies evaluated the effect of probiotics on vascular function or structure [43-45]. Malik et al. [44] and Rezazadeh et al. [43] observed improvement in endothelial dysfunction, while Szulińska et al. [45] showed improvement in arterial stiffness after probiotic supplementation. Nevertheless, these studies have some limitations as lack of assessment in both sexes and the absence of food intake control.

Other strengths of the present study include an adequate evaluation of dietary intake before (V0) and during the study (V4), the prescription of an individualized energy-restricted diet with similar characteristic for both study groups, and the evaluation of fecal microbiota at the V0 and V4. A challenge of the study is the selection of participants due to the inclusion and exclusion criteria. Some studies have already shown acceptable agreement of PWV provided by Mobil-O-Graph with PWV provided by other noninvasive devices such as SphygmoCor, Arteriograph and Complior [79-81] and even with aortic PWV invasively assessed showing a significant and strong linear correlation $(r=0.81, p<0.001)$ and mean difference of $0.05 \mathrm{~m} / \mathrm{s}$ for repeated oscillometric measurements of aortic PWV [82]. As PWV will be provided by Mobil-OGraph, a device that uses an algorithm based on age and BP, this parameter will not be an independent variable, being a possible limitation when performing some statistical modeling.
In summary, this trial will test the hypothesis that probiotics can potentiate the beneficial effects of energy restriction on cardiometabolic risk factors in obese hypertensive individuals. Therefore, it may help to elucidate the role of probiotics on cardiovascular health.

\section{CONFLICTS OF INTEREST}

The authors declare they have no conflicts of interest.

\section{AUTHORS' CONTRIBUTION}

MRG, KSSP, DCTV, MFN and MRSTK conceived and designed this trial. MFN and MRSTK coordinate and supervise the study. MRG, KSSP and DCTV will collect the data. MRG, KSSP, MFN and MRSTK will do the statistical analysis. MRG, KSSP, DCTV and MRSTK wrote the first draft of the manuscript. WO, MFN and MRSTK provide critical comments on all drafts of the manuscript. All authors reviewed and provided critical comments on drafts. All authors have approved the submitted version. The corresponding author states that all listed authors meet authorship criteria.

\section{FUNDING}

MRSTK will receive a grant from Carlos Chagas Filho Foundation for Research Support at the State of Rio de Janeiro (FAPERJ) for funding this project. This study will be financed in part by the Coordenação de Aperfeiçoamento de Pessoal de Nível Superior Brasil (CAPES) - Finance Code 001.

\section{REFERENCES}

[1] Forouzanfar MH, Afshin A, Alexander LT, Anderson HR, Bhutta ZA, Biryukov S, et al. Global, regional, and national comparative risk assessment of 79 behavioural, environmental and occupational, and metabolic risks or clusters of risks, 1990-2015: a systematic analysis for the Global Burden of Disease Study 2015. Lancet 2016;388:1659-724.

[2] Mills KT, Bundy JD, Kelly TN, Reed JE, Kearney PM, Reynolds K, et al. Global disparities of hypertension prevalence and control: a systematic analysis of population-based studies from 90 countries. Circulation 2016;134:441-50.

[3] Rapsomaniki E, Timmis A, George J, Pujades-Rodriguez M, Shah AD, Denaxas $S$, et al. Blood pressure and incidence of twelve cardiovascular diseases: Lifetime risks, healthy life-years lost, and age-specific associations in 1.25 million people. Lancet 2014;383:1899-911.

[4] Forouzanfar MH, Liu P, Roth GA, Ng M, Biryukov S, Marczak L, et al. Global burden of hypertension and systolic blood pressure of at least 110 to $115 \mathrm{~mm} \mathrm{Hg}, 1990-2015$. JAMA 2017;317: $165-82$.

[5] Lewington S, Clarke R, Qizilbash N, Peto R, Collins R, Prospective Studies Collaboration. Age-specific relevance of usual blood pressure to vascular mortality: a meta-analysis of individual data for one million adults in 61 prospective studies. Lancet 2002;360: 1903-13. 
[6] Whelton PK, Carey RM, Aronow WS, Casey DE, Collins KJ, Dennison Himmelfarb C, et al. 2017 ACC/AHA/AAPA/ABC/ ACPM/AGS/APhA/ASH/ ASPC/NMA/PCNA guideline for the prevention, detection, evaluation, and management of high blood pressure in adults: executive summary: a report of the American college of cardiology/American Heart Association task. Hypertension 2018;71:1269-324.

[7] Williams B, Mancia G, Spiering W, Rosei EA, Azizi M, Burnier M, et al. 2018 ESC/ESH Guidelines for themanagement of arterial hypertension: the Task Force for the management of arterial hypertension of the European Society of Cardiology (ESC) and the European Society of Hypertension (ESH). Eur Heart J 2018;39:3021-104.

[8] Hall JE, do Carmo JM, da Silva AA, Wang Z, Hall ME. Obesity, kidney dysfunction and hypertension: mechanistic links. Nat Rev Nephrol 2019;15:367-85.

[9] Garvey WT, Mechanick JI, Brett EM, Garber AJ, Hurley DL, Jastreboff AM, et al. American association of clinical endocrinologists and American college of endocrinology comprehensive clinical practice guidelines for medical care of patients with obesity. Endocr Pract 2016;22:1-203.

[10] Li P, Wang L, Liu C. Overweightness, obesity and arterial stiffness in healthy subjects: a systematic review and meta-analysis of literature studies. Postgrad Med 2017;129:224-30.

[11] Jia G, Aroor AR, Sowers JR. The role of mineralocorticoid receptor signaling in the cross-talk between adipose tissue and the vascular wall. Cardiovasc Res 2017;113:1055-63.

[12] Appel LJ. The effects of dietary factors on blood pressure. Cardiol Clin 2017;35:197-212.

[13] Neter JE, Stam BE, Kok FJ, Grobbee DE, Geleijnse JM. Influence of weight reduction on blood pressure: a meta-analysis of randomized controlled trials. Hypertension 2003;42:878-84.

[14] Joris PJ, Plat J, Kusters YH, Houben AJ, Stehouwer CD, Schalkwijk $\mathrm{CG}$, et al. Diet-induced weight loss improves not only cardiometabolic risk markers but also markers of vascular function: a randomized controlled trial in abdominally obese men. Am J Clin Nutr 2017;105:23-31.

[15] Bianchi VE. Weight loss is a critical factor to reduce inflammation. Clin Nutr ESPEN 2018;28:21-35.

[16] Tang WH, Kitai T, Hazen SL. Gut microbiota in cardiovascular health and disease. Circ Res 2018;120:1183-96.

[17] Moran-Ramos S, López-Contreras BE, Canizales-Quinteros S. Gut microbiota in obesity and metabolic abnormalities: a matter of composition or functionality? Arch Med Res 2017;48:735-53.

[18] Ascher S, Reinhardt C. The gut microbiota: an emerging risk factor for cardiovascular and cerebrovascular disease. Eur J Immunol 2018;48:564-75.

[19] Kim S, Goel R, Kumar A, Qi Y, Lobaton G, Hosaka K, et al. Imbalance of gut microbiome and intestinal epithelial barrier dysfunction in patients with high blood pressure. Clin Sci (Lond) 2018;132:701-18.

[20] Battson ML, Lee DM, Weir TL, Gentile CL. The gut microbiota as a novel regulator of cardiovascular function and disease. J Nutr Biochem 2018;56:1-15.

[21] Dan X, Mushi Z, Baili W, Han L, Enqi W, Huanhu Z, et al. Differential analysis of hypertension-associated intestinal microbiota. Int J Med Sci 2019;16:872-81.

[22] Menni C, Lin C, Cecelja M, Mangino M, Matey-Hernandez ML, Keehn L, et al. Gut microbial diversity is associated with lower arterial stiffness in women. Eur Heart J 2018;39:2390-7.
[23] Cani PD, Amar J, Iglesias MA, Poggi M, Knauf C, Bastelica D, et al. Metabolic endotoxemia initiates obesity and insulin resistance. Diabetes 2007;56:1761-72.

[24] Rajani C, Jia W. Disruptions in gut microbial-host co-metabolism and the development of metabolic disorders. Clin Sci (Lond) 2018;132:791-811.

[25] Organ CL, Otsuka H, Bhushan S, Wang Z, Bradley J, Trivedi R, et al. Choline diet and its gut microbe-derived metabolite, trimethylamine n-oxide, exacerbate pressure overload-induced heart failure. Circ Hear Fail 2016;9:139-48.

[26] Senthong V, Wang Z, Fan Y, Wu Y, Hazen SL, Tang WHW. Trimethylamine $N$-oxide and mortality risk in patients with peripheral artery disease. J Am Heart Assoc 2016;5:e004237.

[27] Geng J, Yang C, Wang B, Zhang X, Hu T, Gu Y, et al. Trimethylamine $\mathrm{N}$-oxide promotes atherosclerosis via CD36dependent MAPK/JNK pathway. Biomed Pharmacother 2018;97:941-7.

[28] Hill C, Guarner F, Reid G, Gibson GR, Merenstein DJ, Pot B, et al. Expert consensus document: The international scientific association for probiotics and prebiotics consensus statement on the scope and appropriate use of the term probiotic. Nat Rev Gastroenterol Hepatol 2014;11:506-14.

[29] Zhang Q, Wu Y, Fei X. Effect of probiotics on body weight and body-mass index: a systematic review and meta-analysis of randomized, controlled trials. Int J Food Sci Nutr 2016;67:571-80.

[30] Park S, Bae JH. Probiotics for weight loss: a systematic review and meta-analysis. Nutr Res 2015;35:566-75.

[31] Sun J, Buys N. Effects of probiotics consumption on lowering lipids and CVD risk factors: a systematic review and meta-analysis of randomized controlled trials. Ann Med 2015;47:430-40.

[32] Sabico S, Al-Mashharawi A, Al-Daghri NM, Yakout S, Alnaami AM, Alokail MS, et al. Effects of a multi-strain probiotic supplement for 12 weeks in circulating endotoxin levels and cardiometabolic profiles of medication naïve T2DM patients: a randomized clinical trial. J Transl Med 2017;15:249.

[33] Kim J, Yun JM, Kim MK, Kwon O, Cho B. Lactobacillus gasseri BNR17 supplementation reduces the visceral fat accumulation and waist circumference in obese adults: a randomized, double-blind, placebo-controlled trial. J Med Food 2018;21:454-61.

[34] Borgeraas H, Johnson LK, Skattebu J, Hertel JK, Hjelmesæth J. Effects of probiotics on body weight, body mass index, fat mass and fat percentage in subjects with overweight or obesity: a systematic review and meta-analysis of randomized controlled trials. Obes Rev 2018;19:219-32.

[35] Koutnikova H, Genser B, Monteiro-Sepulveda M, Faurie JM, Rizkalla S, Schrezenmeir J, et al. Impact of bacterial probiotics on obesity, diabetes and non-alcoholic fatty liver disease related variables: a systematic review and meta-analysis of randomised controlled trials. BMJ Open 2019;9:e017995.

[36] Raygan F, Rezavandi Z, Bahmani F, Ostadmohammadi V, Mansournia MA, Tajabadi-Ebrahimi M, et al. The effects of probiotic supplementation on metabolic status in type 2 diabetic patients with coronary heart disease. Diabetol Metab Syndr 2018;10:51.

[37] Kobyliak N, Falalyeyeva T, Mykhalchyshyn G, Kyriienko D, Komissarenko I. Effect of alive probiotic on insulin resistance in type 2 diabetes patients: randomized clinical trial. Diabetes Metab Syndr 2018;12:617-24.

[38] He J, Zhang F, Han Y. Effect of probiotics on lipid profiles and blood pressure in patients with type 2 diabetes: a meta-analysis of RCTs. Medicine (Bailtimore) 2017;96:e9166. 
[39] Tanaka M. Improving obesity and blood pressure. Hypertens Res 2020;43:79-89.

[40] Sabico S, Al-Mashharawi A, Al-Daghri NM, Wani K, Amer OE, Hussain DS, et al. Effects of a 6-month multi-strain probiotics supplementation in endotoxemic, inflammatory and cardiometabolic status of T2DM patients: a randomized, double-blind, placebo-controlled trial. Clin Nutr 2019;38:1561-9.

[41] Dong JY, Szeto IM, Makinen K, Gao Q, Wang J, Qin LQ, et al. Effect of probiotic fermented milk on blood pressure: a meta-analysis of randomised controlled trials. Br J Nutr 2013;110:1188-94.

[42] Khalesi S, Sun J, Buys N, Jayasinghe R. Effect of probiotics on blood pressure: a systematic review and meta-analysis of randomized, controlled trials. Hypertension 2014;64:897-903.

[43] Rezazadeh L, Gargari BP, Jafarabadi MA, Alipour B. Effects of probiotic yogurt on glycemic indexes and endothelial dysfunction markers in patients with metabolic syndrome. Nutrition 2019;62:162-8.

[44] Malik M, Suboc TM, Tyagi S, Salzman N, Wang J, Ying R, et al. Lactobacillus plantarum 299v supplementation improves vascular endothelial function and reduces inflammatory biomarkers in men with stable coronary artery disease. Circ Res 2018;123: 1091-102.

[45] Szulińska M, Łoniewski I, Skrypnik K, Sobieska M, Korybalska K, Suliburska J, et al. Multispecies probiotic supplementation favorably affects vascular function and reduces arterial stiffness in obese postmenopausal women-a 12-week placebo-controlled and randomized clinical study. Nutrients 2018;10:1672.

[46] Institute of Medicine (IOM). Dietary reference intakes for energy, carbohydrate, fiber, fat, fatty acids, cholesterol, protein, and amino acids. Washington D.C., USA: The National Academies Press; 2005, p. 1357.

[47] Instituto Brasileiro de Geografia e Estatística - IBGE. Pesquisa de Orçamentos Familiares 2008-2009: Tabelas de Composição Nutricional dos Alimentos Consumidos no Brasil [Internet], vols. 39; 2011. p. 35-340. Available from: https://biblioteca.ibge. gov.br/visualizacao/livros/liv50002.pdf.

[48] Universidade Estadual de Campinas (UNICAMP). Tabela Brasileira de Composição de Alimentos - TACO [Internet]; 2011, pp. 26-155. Available from: http://www.nepa.unicamp.br/ taco/contar/taco_4_edicao_ampliada_e_revisada.pdf?arquivo=taco_4_versao_ampliada_e_revisada.pdf.

[49] World Health Organization (WHO). Obesity: preventing and managing the global epidemic. Geneva: World Health Organization; 2000, p. 252. Available from: https://www.who.int/ nutrition/publications/obesity/WHO_TRS_894/en/.

[50] World Health Organization (WHO). WHO| Waist Circumference and Waist-Hip Ratio. Report of a WHO Expert Consultation. Geneva: World Health Organization; 2008. Available from: http:// www.who.int.

[51] Onat A, Hergenç G, Yüksel H, Can G, Ayhan E, Kaya Z, et al. Neck circumference as a measure of central obesity: associations with metabolic syndrome and obstructive sleep apnea syndrome beyond waist circumference. Clin Nutr 2009;28:46-51.

[52] Kyle UG, Bosaeus I, De Lorenzo AD, Deurenberg P, Elia M, Manuel Gómez J, et al. Bioelectrical impedance analysis-part II: utilization in clinical practice. Clin Nutr 2004;23:1430-53.

[53] Barbosa-Silva MCG, Barros AJD. Bioelectrical impedance analysis in clinical practice: a new perspective on its use beyond body composition equations. Curr Opin Clin Nutr Metab Care 2005;8:311-7.
[54] Segal KR, Van Loan M, Fitzgerald PI, Hodgdon JA, Van Itallie TB. Lean body mass estimation by bioelectrical impedance analysis: a four-site cross-validation study. Am J Clin Nutr 1988;47:7-14.

[55] Gray DS, Bray GA, Gemayel N, Kaplan K. Effect of obesity on bioelectrical impedance. Am J Clin Nutr 1989;50:255-60.

[56] Kaul S, Rothney MP, Peters DM, Wacker WK, Davis CE, Shapiro MD, et al. Dual-energy X-ray absorptiometry for quantification of visceral fat. Obesity (Silver Spring) 2012;20:1313-8.

[57] Matsudo S, Araújo T, Matsudo V, Andrade D, Andrade E, Oliveira LC, et al. Questionário Internacional De Atividade Física (Ipaq): Estudo De Validade E Reprodutibilidade No Brasil. Rev Bras Atividade Física Saúde 2001;6:5-18.

[58] Friedewald WT, Levy RI, Fredrickson DS. Estimation of the concentration of low-density lipoprotein cholesterol in plasma, without use of the preparative ultracentrifuge. Clin Chem 1972;18:499-502.

[59] Matthews DR, Hosker JP, Rudenski AS, Naylor BA, Treacher DF, Turner RC. Homeostasis model assessment: insulin resistance and $\beta$-cell function from fasting plasma glucose and insulin concentrations in man. Diabetologia 1985;28:412-9.

[60] Jardim PC, Souza WK, Lopes RD, Brandão AA, Malachias MV, Gomes MM, et al. I RBH - first brazilian hypertension registry. Arq Bras Cardiol 2016;107:93-8 [Article in English, Portuguese].

[61] Souza CA de, Simões R, Borges KBG, Oliveira AN, Zogeib JB, Alves B, et al. Arterial stiffness use for early monitoring of cardiovascular adverse events due to anthracycline chemotherapy in breast cancer patients. A pilot study. Arq Bras Cardiol 2018;111:721-8 [Article in English, Portuguese].

[62] Asmar R, Benetos A, Topouchian J, Laurent P, Pannier B, Brisac AM, et al. Assessment of arterial distensibility by automatic pulse wave velocity measurement: validation and clinical application studies. Hypertension 1995;26:485-90.

[63] Wilkinson IB, MacCallum H, Flint L, Cockcroft JR, Newby DE, Webb DJ. The influence of heart rate on augmentation index and central arterial pressure in humans. J Physiol 2000;525:263-70.

[64] Mahé G, Humeau-Heurtier A, Durand S, Leftheriotis G, Abraham P. Assessment of skin microvascular function and dysfunction with laser speckle contrast imaging. Circ Cardiovasc Imaging 2012;5:155-63.

[65] Khalesi S, Bellissimo N, Vandelanotte C, Williams S, Stanley D, Irwin C. A review of probiotic supplementation in healthy adults: helpful or hype? Eur J Clin Nutr 2019;73:24-37.

[66] O'Morain VL, Ramji DP. The potential of probiotics in the prevention and treatment of atherosclerosis. Mol Nutr Food Res 2020;64:e1900797.

[67] Wang L, Guo MJ, Gao Q, Yang JF, Yang L, Pang XL, et al. The effects of probiotics on total cholesterol. Medicine (Baltimore) 2018;97:e9679.

[68] Yan S, Tian Z, Li M, Li B, Cui W. Effects of probiotic supplementation on the regulation of blood lipid levels in overweight or obese subjects: a meta-analysis. Food Funct 2019;10: 1747-59.

[69] Shimizu M, Hashiguchi M, Shiga T, Tamura H, Mochizuki M. Meta-analysis: effects of probiotic supplementation on lipid profiles in normal to mildly hypercholesterolemic individuals. PLoS One 2015;10:e0139795.

[70] Jung SP, Lee KM, Kang JH, Yun SI, Park HO, Moon Y, et al. Effect of Lactobacillus gasseri BNR17 on overweight and obese adults: a randomized, double-blind clinical trial. Korean J Fam Med 2013;34:80-9. 
[71] Minami J, Kondo S, Yanagisawa N, Odamaki T, Xiao J, Abe F, et al. Oral administration of Bifidobacterium breve B-3 modifies metabolic functions in adults with obese tendencies in a randomised controlled trial. J Nutr Sci 2015;4:e17.

[72] Sharafedtinov KK, Plotnikova OA, Alexeeva RI, Sentsova TB, Songisepp E, Stsepetova J, et al. Hypocaloric diet supplemented with probiotic cheese improves body mass index and blood pressure indices of obese hypertensive patients-a randomized double-blind placebo-controlled pilot study. Nutr J 2013;12:138.

[73] Lee SJ, Bose S, Seo JG, Chung WS, Lim CY, Kim H. The effects of co-administration of probiotics with herbal medicine on obesity, metabolic endotoxemia and dysbiosis: a randomized double-blind controlled clinical trial. Clin Nutr 2014;33: 973-81.

[74] Andreasen AS, Larsen N, Pedersen-Skovsgaard T, Berg RM, Møller K, Svendsen KD, et al. Effects of Lactobacillus acidophilus NCFM on insulin sensitivity and the systemic inflammatory response in human subjects. Br J Nutr 2010;104:1831-8.

[75] Kadooka Y, Sato M, Imaizumi K, Ogawa A, Ikuyama K, Akai Y, et al. Regulation of abdominal adiposity by probiotics (Lactobacillus gasseri SBT2055) in adults with obese tendencies in a randomized controlled trial. Eur J Clin Nutr 2010;64:636-43.

[76] Simon MC, Strassburger K, Nowotny B, Kolb H, Nowotny P, Burkart V, et al. Intake of Lactobacillus reuteri improves incretin and insulin secretion in glucose-tolerant humans: a proof of concept. Diabetes Care 2015;38:1827-34.

[77] Li T, Chen Y, Gua C, Li X. Elevated circulating trimethylamine $\mathrm{N}$-oxide levels contribute to endothelial dysfunction in aged rats through vascular inflammation and oxidative stress. Front Physiol 2017;8:350.

[78] Ma J, Li H. The role of gut microbiota in atherosclerosis and hypertension. Front Pharmacol 2018;9:1082.

[79] Vaios V, Georgianos PI, Pikilidou MI, Eleftheriadis T, Zarogiannis S, Papagianni A, et al. Accuracy of a newly-introduced oscillometric device for the estimation of arterial stiffness indices in patients on peritoneal dialysis: a preliminary validation study. Adv Perit Dial 2018;34:24-31.

[80] Georgianos P, Vaios V, Pikilidou M, Papagianni A, Zebekakis P, Liakopoulos V. A comparison study between Mobil-O-Graph and sphygmocor devices in assessing aortic systolic pressure and pulse wave velocity in peritoneal dialysis patients. J Hypertens 2018;36:e80.

[81] Benas D, Kornelakis M, Triantafyllidi H, Kostelli G, Pavlidis G, Varoudi M, et al. Pulse wave analysis using the Mobil-O-Graph, Arteriograph and Complior device: a comparative study. Blood Press 2019;28:107-13.

[82] Hametner B, Wassertheurer S, Kropf J, Mayer C, Eber B, Weber T. Oscillometric estimation of aortic pulse wave velocity: comparison with intra-aortic catheter measurements. Blood Press Monit 2013;18:173-6. 